\title{
Radiologic Resectability Assessment in Pancreatic Cancer
}

\section{Radiologische Einschätzung der Resektabilität beim Pankreaskarzinom}

Authors

Affiliations
T. Denecke ${ }^{1}$, C. Grieser ${ }^{1}$, P. Neuhaus ${ }^{2}$, M. Bahra ${ }^{2}$

Institute of Radiology, Campus Virchow-Klinikum, Charité - Universitätsmedizin Berlin

Department of General, Visceral, Vascular and Thoracic Surgery, Campus Virchow-Klinikum, Charité - Universitätsmedizin Berlin

Key words
pancreas
CT
MR imaging
resectability
cancer
staging

received $\quad 2.7 .2012$

accepted 25.6.2013

Bibliography

Dol http://dx.doi.org/

10.1055/s-0033-1350190

Published online: 30.9.2013

Fortschr Röntgenstr 2014; 186 :

23-29 @ Georg Thieme Verlag

KG Stuttgart · New York .

ISSN 1438-9029

\section{Correspondence}

Dr. Timm Denecke

Klinik für Radiologie, Campus

Virchow-Klinikum, Charité -

Universitätsmedizin Berlin

Augustenbuerger Platz 1

13353 Berlin

Germany

Tel.: ++49/(0) 30/450557001

Fax: $++49 /(0) 30 / 450557901$

timm.denecke@charite.de

\section{Zusammenfassung \\ $\nabla$}

Für Patienten mit duktalem Adenokarzinom des Pankreas stellt die vollständige Tumorresektion nach wie vor die einzige potenziell kurative Therapieoption dar. Zur Klärung ob eine Tumorresektion möglich ist gilt die chirurgische Exploration als Goldstandard. Die radiologische Einschätzung der Resektabilität vor der Operation ist von entscheidender Bedeutung, da sie viele eindeutig irresektable Fälle präoperativ identifizieren kann und zur Planung des chirurgischen Eingriffs unverzichtbar geworden ist. Die Weiterentwicklungen chirurgischer Techniken und bildgebender Methoden verlangen eine kontinuierliche Neubewertung der Kriterien für eine Einschätzung der Resektabilität anhand radiologischer Diagnostik. Im Folgenden werden die Kriterien für die Resektionsplanung und das chirurgische Vorgehen beschrieben sowie die Rolle der Radiologie bei einigen innovativen chirurgischen Therapiekonzepten erläutert.

\section{Introduction \\ $\nabla$}

Although notable progress in diagnosis and therapy has been made in recent years, the 5-year survival of patients diagnosed with ductal adenocarcinoma of the pancreas is still less than $5 \%$ [1]. To date, surgery is the only curative option for patients suffering from this aggressive entity. Nowadays in high-volume centers, this procedure can be performed with a mortality of $1-3 \%$ and morbidity of about $40 \%$ [2]. However, only a minority of patients is resectable and 5-year survival rates of more than $20 \%$ after resection are rare [2]. Radical resection of the tumor reaching negative resection margins is one of the strongest predictors for long-term survival [3]. Surgical exploration is the gold standard to determine unresectability. However, it is crucial to avoid passing the point

\section{Abstract \\ $\nabla$}

Complete tumor resection is still the only potentially curative therapy option for patients with ductal adenocarcinoma of the pancreas. Surgical exploration is the gold standard for the determination of tumor resectability. Radiological resectability assessment is of great importance because many clearly unresectable cases can be identified preoperatively and it became essential for surgical planning. The evolving surgical and radiological techniques demand a continuous reappraisal of radiological criteria in resectability assessment. In the following, the criteria for resection planning are described along with surgical management and the role of radiology in some innovative surgical concepts is explained.

Citation Format:

- Denecke T, Grieser C, Neuhaus P etal. Radiologic Resectability Assessment in Pancreatic Cancer. Fortschr Röntgenstr 2014; 186: 23-29

of no return during explorative surgery. Otherwise, the resection has to be completed with the result of an R2-resection which implicates perioperative risk and does not improve prognosis [4]. Therefore, radiological assessment of resectability is an indispensible standard procedure before surgery with the goal to plan surgery by displaying the critical zones or to identify clearly unresectable patients.

Surgical techniques have evolved significantly over the recent decades with attempts of more aggressive and radical resection. This is paralleled by technical advances in imaging technology regarding computed tomography (CT) and magnetic resonance imaging (MRI), which are the radiological modalities most frequently requested by surgeons for preoperative diagnostics and resectability assessment [5 - 7]. Therefore, a continuous 
reappraisal of radiological methods and criteria in resectability assessment and exact knowledge of current surgical techniques are necessary for radiologists to give the correct advice to surgeons.

\section{How to resect \\ $\nabla$}

Pancreatic cancer is located in $70 \%$ of cases in the pancreatic head, in $20 \%$ of cases in the body and $10 \%$ are located in the pancreatic tail. The oncologically radical types of resection for pancreatic head cancer are en-bloc resection of the pancreatic head and duodenum with partial gastrectomy (Kausch-Whipple procedure) or, today's standard, pylorus preserving without gastric resection (Traverso-Longmire) [2]. For cancer of the pancreatic body and tail, a left pancreatectomy with splenectomy is performed [2]. Depending on the dimension of a left-sided carcinoma, the resection has to be extended towards the pancreatic head to reach tumor-free resection margins (subtotal left-sided pancreatectomy or total pancreatectomy). If the carcinoma is found to be of multilocular origin, a total pancreatectomy plus splenectomy is indicated to ensure complete removal of the tumor. Due to the absence of symptoms such as jaundice or gastric outlet stenosis, it is not unusual to diagnose left-sided pancreatic tumors at an advanced stage with involvement of adjacent organs such as the colon or stomach. In this case, multivisceral resection with complete removal of the tumor remains an option because the median survival is comparable to that of patients after standard pancreatic resections [8].

It can be deduced from the aforementioned characteristics of the different surgical options that location, intrapancreatic extent, and extension into adjacent tissues are the key information for surgical decision making. Regarding the extrapancreatic extent, both contrast-enhanced multiplanar CT and MRI are capable of displaying the tumor as well as the surrounding retroperitoneal and mesenteric fat, stomach, and bowel wall. Here, in case of absent or depleted separating fat planes, blurred or abolished boundary surfaces of tumor-adjacent tissues may indicate infiltration.

Inside the pancreas, the highest possible contrast of the tumor to the surrounding pancreatic tissue is needed. For CT, it has been shown that after intravenous application of contrast media, pancreatic tissue enhances early, while ductal adenocarcinoma of the pancreas typically shows slow contrast accumulation [9]. The highest difference in radiodensity between tumor and pancreas is reached with a scan delay of approximately 40 seconds after the start of contrast administration [9] ( $\bullet$ Fig. 1). This contrast phase is therefore indispensable for preoperative CT imaging of pancreatic cancer, and the results can be transferred to dynamic contrast-enhanced MRI as well, which is equally suited to detect and delineate tumors [10]. The use of bolus tracking can improve the correct timing of this pancreatic parenchymal phase in the individual patient by using an interval of approximately $25 \mathrm{sec}-$ onds after bolus arrival in the abdominal aorta [11].

\section{Vessel invasion \\ $\nabla$}

The most common finding when determining unresectability besides the presence of metastases is the local invasion of major vascular structures by the primary tumor. In the case of pancreatic left resection, splenic vessels, even though their invasion is a

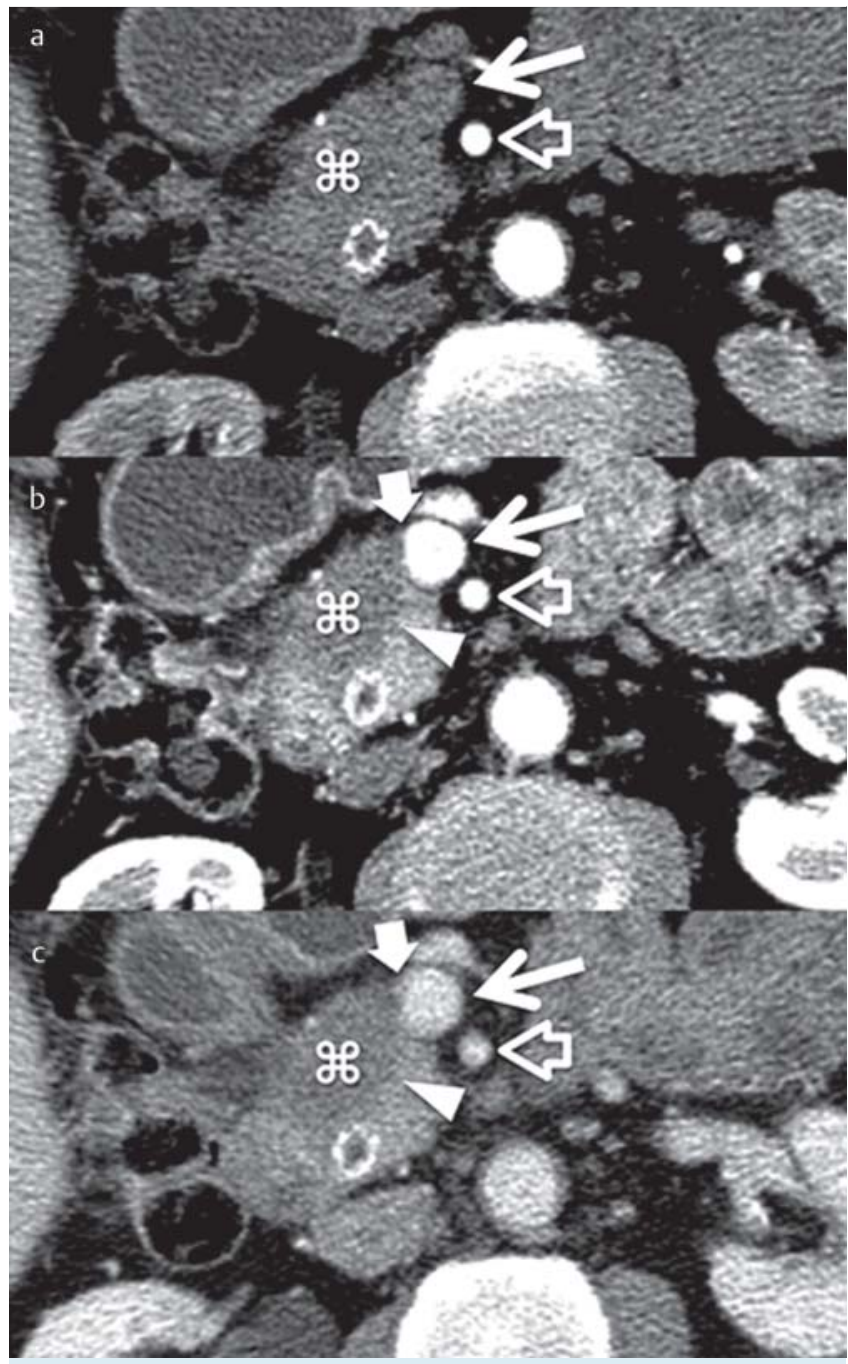

Fig. 1 Dynamic computed tomography (a $20 \mathrm{sec}$. delay; b $45 \mathrm{sec}$. delay; c 70 sec. delay) demonstrating contrast intensification of pancreatic ductal adenocarcinoma (asterisk). The best delineation of the tumor against the pancreatic parenchyma (arrow head) is seen with a delay of $45 \mathrm{sec}$. because of quick contrast uptake in the pancreas and slow accumulation in the tumor. This allows detailed visualization of tumor/vessel contact (block arrow) towards the superior mesenteric vein (arrow). The superior mesenteric artery (empty arrow) is surrounded by a fat plane indicating noninvolvement. Note the stent in the choledochal duct.

Abb. 1 Dynamische Computertomografie (a 20 s Verzögerung, b 45 s Verzögerung, c 70 s Verzögerung) zeigt die Kontrastverstärkung bei duktalem Adenokarzinom des Pankreas (Stern). Die beste Abgrenzbarkeit gegenüber dem Pankreasparenchym (Pfeilspitze) besteht bei $45 \mathrm{~s}$ Verzögerung wegen der raschen Kontrastmittelaufnahme des Pankreasgewebes und der langsamen Akkumulation im Tumor. Dies ermöglicht eine detaillierte Darstellung des Tumor/Gefäß-Kontaktes (Blockpfeil) zur V. mesenterica sup. (Pfeil). Die A. mesenterica sup. (leerer Pfeil) ist von einer Fettschicht umgeben, demnach ist die Arterie hier sicher tumorfrei. Anmerkung: Stent im D. choledochus.

negative prognostic factor [12], are dispensable and are included in the en-bloc resection of the pancreatic tail and spleen. However, in the case of the most frequent location of pancreatic cancer, i. e., the pancreatic head, the surrounding vascular structures are complex and the arterial supply of the liver, stomach, and bowel, as well as the mesentericoportal venous axis has to be maintained in any kind of pancreatic resection. Many efforts 
have been made to facilitate complete tumor resection despite vessel involvement and technically, it is indeed possible to perform vessel resection and reconstruction. However, the surgical capabilities have to be set in relation to the achievable clinical outcome. With respect to the clinical relevance, a differentiation must be made between venous and arterial involvement $[13,14]$. This is reflected by the current TNM staging system: the T3 category, representing the locally invasive but potentially resectable tumor, includes also focal invasion of the mesentericoportal venous axis, which can be handled surgically, while the T4 category, referring to the locally advanced unresectable tumor, includes invasion of the superior mesenteric artery (SMA) or the celiac axis [15]. The basis for discussion of the surgical options and prognosis related to the local tumor extent is the preoperative imaging with distinct analysis of the local tumor situation.

\section{Veins}

Tumor infiltration of the mesentericoportal axis is common in pancreatic head carcinoma. If the portal vein (PV) resection results in negative resection margins, survival rates similar to those of patients without PV resection can be achieved [16]. For that, tumor involvement of the PV is not a general contraindication for curative pancreatic head resection [13]. To maintain the venous drainage of the bowel after venous resection, several surgical procedures are available for venous reconstruction. These are segmental resection with reanastomosis (with or without interposition of a graft) and wall excision with patch plastic. Exact analysis of the portal venous confluence anatomy and its normal variants in this context is important and can be done with CT [17]. Extensive invasion of the mesenteric vein with separation of its branches as depicted by CT or MRI can even result in unresectability ( $\odot$ Fig. 2, $\odot$ Table 1 ). The intraoperative decision regarding how to manage venous involvement is made to a great part after the point of no return of a pancreatic head resection. This is why distinct preoperative knowledge of the extent of contact between the tumor and the mesentericoportal venous axis is so important.

The radiological appearance of the tumor/vein interface can be with a fat plane between the tumor and the vein securely indicating non-involvement and dissectability, while complete encasement and vessel occlusion are a reliable sign for profound vessel invasion [18]. Any other direct tumor contact to the vessel may indicate invasion or a non-dissectable adhesion and has to be fur- ther characterized ( $\bullet$ Fig. 1). A recent study used simple descriptive criteria of the tumor/vein contact on CT images to predict the actual infiltration depth in the wall of the mesentericoportal veins and prognosis retrospectively in 358 patients resected for pancreatic cancer [19]. An increasing number and increasing depth of vessel wall invasions were found with increasing tumor-related narrowing of the vessel lumen (invasion into tunica media or deeper: no narrowing, $0 \%$; unilateral narrowing, $27 \%$; bilateral narrowing, $42 \%$; obstruction with collaterals, $63 \%$ ), par-

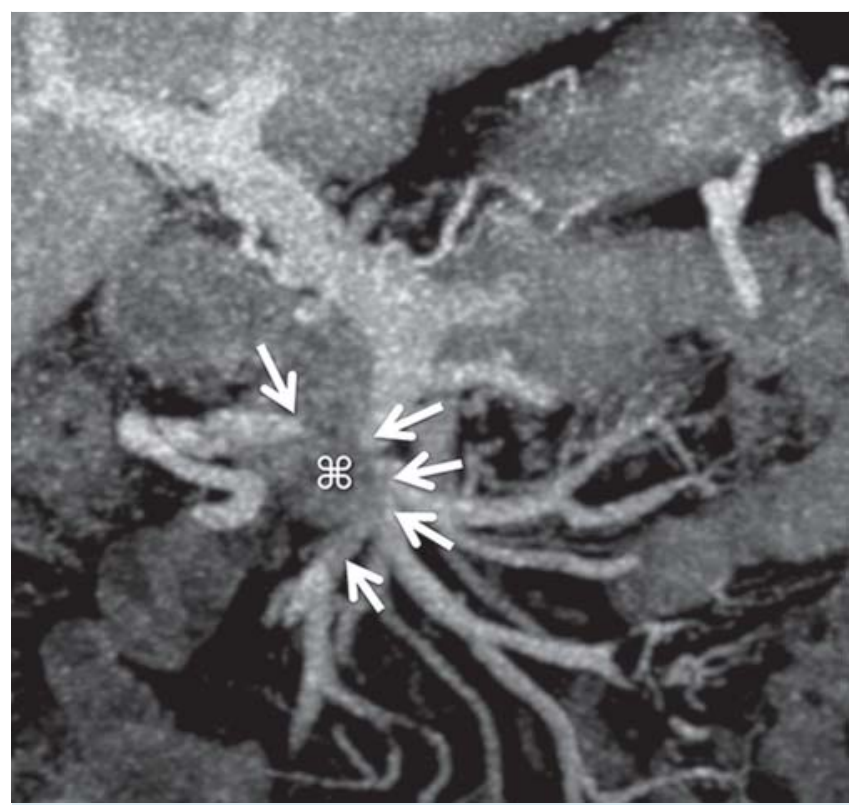

Fig. 2 Carcinoma of the pancreatic head invading the superior mesenteric vein (CT, coronal MIP). The tumor (asterisk) occludes several main branches of the mesenteric vein (arrows). In this case, spontaneous collateralization of all venous territories after resection cannot be expected to be sufficient and surgical reconstruction of all relevant branches is problematic resulting in unresectability upon explorative surgery.

Abb. 2 Pankreaskopfkarzinom mit Infiltration der V. mesenterica superior (CT, koronare MIP). Der Tumor (Stern) verschließt mehrere Hauptäste der Mesenterialvene (Pfeile). In diesem Fall kann eine ausreichende Kollateralisierung nach Resektion nicht erwartet werden und die chirurgische Rekonstruktion von allen relevanten Ästen ist problematisch mit dem Ergebnis der Irresektabilität nach explorativer Laparotomie.

Table 1 Signs of unresectability on computed tomography and magnetic resonance imaging examinations.

Tab. 1 Zeichen der Irresektabilität in der Computertomografie und der Magnet-Resonanz-Tomografie

\begin{tabular}{|c|c|c|c|}
\hline \multicolumn{3}{|c|}{ radiological signs of unresectability } & \multirow{3}{*}{$\begin{array}{l}\text { exceptions } \\
\text { left pancreatectomy with resection of the celiac axis for } \\
\text { cancers of the body and tail can be considered if superior } \\
\text { mesenteric, gastroduodenal, and proper hepatic arteries are } \\
\text { free }\end{array}$} \\
\hline \multirow[t]{7}{*}{ vessel involvement } & \multirow[t]{4}{*}{ arteries } & celiac trunk & \\
\hline & & common hepatic artery & \\
\hline & & proper regular or aberrant hepatic artery & \\
\hline & & superior mesenteric artery & \\
\hline & \multirow[t]{3}{*}{ veins } & superior mesenteric vein at its branching & if surgical reconstruction is possible \\
\hline & & inferior vena cava & \\
\hline & & renal vein & \\
\hline \multirow[t]{2}{*}{ metastases } & \multicolumn{2}{|c|}{ hepatic or other hematogenous metastases } & \\
\hline & \multicolumn{2}{|c|}{ peritoneal carcinomatosis } & \\
\hline $\begin{array}{l}\text { invasion of adjacent } \\
\text { organs }\end{array}$ & \multicolumn{2}{|c|}{ spleen, colon, small bowel, stomach, adrenal gland } & individual consideration if R0-resection seems possible \\
\hline
\end{tabular}


alleled by a significantly worse prognosis for patients with bilateral narrowing or obstruction compared with no or unilateral narrowing of the vein [19]. It has been shown that the use of multiplanar image reconstruction enhances accuracy when determining vein invasion [20]. Reporting the findings not only by description and axial images but also by multiplanar or threedimensional reconstructed images helps the surgeon to plan the procedure regarding complexity, duration, and material needed.

\section{Arteries}

Visceral arteries that are commonly affected by tumor growth are the SMA, the common hepatic artery (CHA) and the celiac artery (celiac trunk). Additional arterial resection during pancreatic head resection is associated with significantly increased perioperative mortality and poor survival compared to patients without necessity for additional arterial resection [21]. Arterial invasion is therefore considered an unresectability criterion ( $\bullet$ Table 1 ).

CT angiography (CTA) and MR angiography (MRA) are the methods of choice as they display both the tumor and the vessel at high image quality $[22,23]$. An early study on CT in the preoperative evaluation of 25 patients with pancreatic cancer showed that the extent of circumferential tumor growth around the artery correlates with vessel wall invasion [24]. Tumor contact of more than half of the artery circumference and/or vessel constriction indicated unresectability at this artery segment with a sensitivity and specificity of $100 \%$. In case of lesser tumor contact without constriction, the tumor was still surgically unresectable at half of the evaluated arteries [24]. A contemporary study used a distinct analysis of the tumor/vessel interface describing it as a convex or concave contact [18]. Again, in the case of contact to the vessel, it was difficult to predict vessel wall invasion. This underlines that between separating the fat plane ( $\bullet$ Fig. 1) and vessel encasement, there is a gray zone of tumor contact to the vessel without a clear-cut differentiation of cases with and without arterial wall infiltration.

In contrast to the devices used in the studies cited above, new multidetector CT scanners with fewer movement artifacts and higher resolution enable high-quality three-dimensional multiplanar and curved image reconstruction. This facilitates improved depiction of arterial constrictions as well as distinct assessment of circumferential and longitudinal tumor contact independent of the vessel orientation. In a recent study evaluating the involvement of the SMA, the CHA, and the celiac trunk with multidetector CT using the traditional criteria of circumferential tumor contact and vessel constriction in 70 pancreatic cancer patients, the sensitivity and specificity were increased from $88 \%$ and $94 \%$ for axial images to $100 \%$ and $93 \%$ for additional multiplanar reconstructions [20]. Other recent studies showed similar results with high accuracy for the assessment of arterial invasion for CT and even for MRI using latest generation devices $[10,25,26]$. These improvements help to increase the rate of correct indications for and successful completions of open surgery with curative intent in pancreatic cancer patients [27]. However, despite the improvements of imaging in this respect, its remaining inaccuracy regarding arterial involvement demands surgical exploration, at least in equivocal cases, as this is still the gold standard in determining resectability.

\section{Arterial variants}

In pancreatic head resection, it is decisive to know about the individual arterial anatomy. Variants of hepatic arteries are common and can be relevant because tumor contact can occur at im-

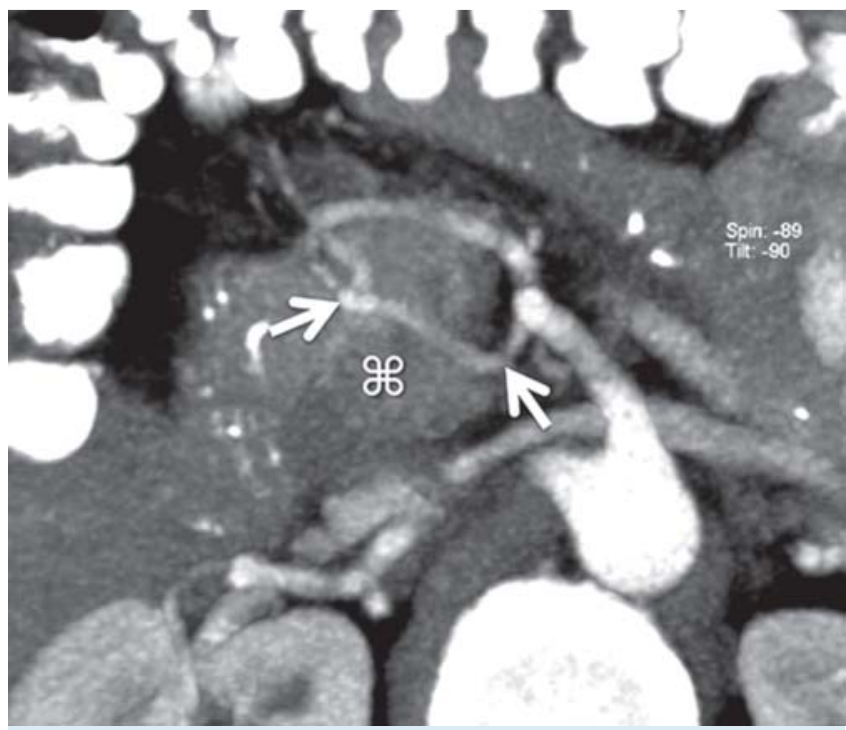

Fig. 3 Rare arterial variant with intrapancreatic aberrant right hepatic artery (arrows) arising from the superior mesenteric artery through the pancreatic head in close proximity to the pancreatic head tumor (asterisk) to the liver (CT, axial MIP).

Abb. 3 Seltene arterielle Normvariante mit intrapankreatischer aberranter rechter Leberarterie (Pfeile) die aus der A. mesenterica superior durch den Pankreaskopf in enger Lagebeziehung zu einem Pankreaskopfkarzinom (\&) zur Leber zieht (CT, axiale MIP)

portant arteries, which are not where the radiologist and the surgeon expect them to be [26]. Conditions which may lead to impaired arterial blood supply of the liver after pancreatic head resection are, e.g. preexisting severe stenosis of the celiac axis which becomes relevant after cutting off the collateral flow from the gastroduodenal artery (GDA) or accidental injury of an aberrant hepatic artery arising from the SMA behind or - rarely - inside the pancreatic head ( $\bullet$ Fig. 3). Tumor infiltration of such an artery is a contraindication for resection just as of the SMA or a regular $\mathrm{CHA}$ ( Table $\mathbf{1}$ ).

As MRA and even more so CTA are highly accurate in displaying the arterial anatomy in the upper abdomen preoperatively, it is obligatory to report the relevant arterial anatomy in detail to the surgeon $[22,26,28]$.

\section{Metastases}

$\nabla$

According to the German S3 guideline, pancreatic adenocarcinoma with hematogenous metastases or peritoneal spread is unresectable regardless of the local tumor extent since it does not improve the overall prognosis [13]. Palliative resection despite present metastases is currently being debated but is still not recommended outside studies. Thus, the exclusion of metastatic spread remains an important part of resectability assessment by imaging and surgical exploration ( $\bullet$ Table 1 ).

\section{Peritoneum}

Regarding the peritoneal spread of pancreatic cancer, preoperative detection is problematic as at an early stage these lesions may appear in the form of small flat spots on the peritoneal surface, without sufficient dimensions to become visible on endoscopic ultrasound (EUS), CT, or MRI. Imaging is limited to the depiction of nodular lesions large enough to pass partial volume effects and to 
be differentiated from the adjacent structures, such as bowel wall or liver surface [29]. A recent study using mostly CT (95\%) for preoperative staging showed an overall rate of unanticipated peritoneal spread discovered during surgery of $5 \%$ in 487 patients [30]. Positron emission tomography with F18-Fluorodeoxyglucose (FDG-PET), initially promising to overcome these problems, did not perform better than CT for the same reasons [31]. Often, only indirect findings, such as small amounts of free peritoneal fluid, can be depicted to raise the suspicion for peritoneal spread. Such findings and other risk factors for the presence of unanticipated peritoneal spread, like large primary tumors and tumor location in the pancreatic body or tail, should prompt the surgeon to start with laparoscopy instead of laparotomy in order to keep the trauma minimal in case of termination of the exploration [32].

\section{Liver}

While CT has not shown any major improvement of the detection rates of liver metastases over the recent decade, MRI has experienced innovations like fast $3 \mathrm{D}$ sequences and diffusion-weighted imaging (DWI) resulting in an increase of sensitivity from $70.2 \%$ until 2004 to $84.9 \%$ until 2010, which is superior to CT (75\%, metaanalysis on colorectal cancer metastases) [33]. For pancreatic cancer, a recent study reported a rate of unanticipated liver metastases of $12 \%$ after negative preoperative imaging (mostly CT, $95 \%$ ) [30]. Furthermore, the rate of unanticipated hepatic and peritoneal metastases increased significantly from $10 \%$ in patients who had been operated within 3 weeks after imaging to $20 \%, 25 \%$, and $35 \%$ in patients who had undergone surgery during the fourth, fifth, and sixth week after imaging, respectively [30]. Therefore, high-quality imaging of the liver and abdomen is needed shortly before surgery to avoid false-negative results. High-quality imaging means contrast-enhanced dynamic scanning using CT and/or MRI and, in the case of MRI, DWI besides the standard sequences $[34,35]$. For both CT and MRI these prerequisites for liver imaging are compatible with pancreatic imaging optimized for resectability assessment. FDG-PET has the strength of a high specificity but a striking lack of sensitivity is reported regarding small liver metastases [35]. Therefore, FDG-PET is currently not the method of choice for resectability assessment of pancreatic cancer $[13,36]$.

\section{Lymph nodes}

Pancreatic cancer resection with a standard lymphadenectomy includes the removal of lymph nodes in the peripancreatic region, along the hepatoduodenal ligament, the celiac trunk, and the SMA. Lymphatic metastases occur frequently and early with lymph node involvement in $75 \%$ of pT3 tumors $[37,38]$. In a large population-based study, $\mathrm{N} 1$ disease $(\mathrm{n}=1,507)$ was associated with a significantly worse 5 -year survival rate of $4.3 \%$ compared with $11.3 \%$ in N0 disease $(n=1,971)$, irrespective of other factors like grading, local extension, and number of assessed lymph nodes [39]. Despite this negative prognostic impact, locoregional lymph node metastases of pancreatic adenocarcinoma in general do not preclude a patient from the attempt of curative surgery $[13,39]$. Given the high prevalence of lymphatic metastases, the minor role for unresectability, and the well-known problems of diagnostic imaging in the detection of involved lymph nodes in any kind of cancer, preoperative lymph node staging plays a minor role for surgical decision-making. The accuracy for the detection of lymph node metastasis by diagnostic imaging is limited as shown in a study on the detection of paraaortic lymph node metastases in 69 pancreatic cancer patients with all six lymph node positive cases being negative on CT, MRI, and FDG-PET [39]. Nevertheless, reporting enlarged, spherical, irregular-shaped, centrally necrotic, or otherwise suspicious nodes can be of importance for the surgeon especially when occurring outside the regions of standard lymphadenectomy because extended lymphadenectomy remains an option for these patients [41].

\section{Innovative treatment concepts \\ $\nabla$}

\section{Neoadjuvant therapy}

If radiological signs of locally advanced disease with arterial infiltration are present, the conversion of advanced pancreatic carcinoma from "non-resectable" to resectable seems to be a promising concept [42]. It remains to be seen what significance neoadjuvant treatment (chemotherapy and/or radiotherapy) will have in the future but already now radiologists are faced with the reassessment of resectability after the completion of neoadjuvant therapy.

It is well known from other tumor entities that the accuracy of CT and MRI can be impaired after neoadjuvant treatment [43-45]. Only a few studies have addressed this issue for pancreatic cancer with variable results. An early study concluded that the prediction of resectability by CT after neoadjuvant radiochemotherapy is comparable to cases without preceding therapy [46]. In contrast, a later study from the same group using CT to reassess initially borderline resectable tumors after neoadjuvant chemo- or chemoradiation therapy showed radiographic reduction of vascular involvement in only less than $1 \%$ but an R0-resection rate as high as $80 \%$ [47]. Another recent study confirmed this tendency of overestimation of the local tumor extent by CT and MRI after neoadjuvant therapy [48], while Kim et al. observed some inaccuracy in T-staging by CT after neoadjuvant treatment but only minor effects on the assessment of resectability [49].

\section{Left pancreatic plus celiac trunk resection}

Carcinoma of the body of the pancreas with involvement of the celiac trunk and/or the CHA is considered to be unresectable [13]. A radical distal pancreatectomy with splenectomy and enbloc resection of the celiac trunk without reconstruction of the celiac axis aims at providing a curative approach for these cases ( $\triangle$ Table 1). A recent metaanalysis of this approach showed survival rates equal to regular R0-resections $[50,51]$. The Achilles heel of this procedure is the interruption of the direct arterial blood supply to the liver, bile ducts, and stomach. Despite collateral pathways via the SMA, pancreaticoduodenal arcades, and the GDA, arterial perfusion of critical organs can be compromised after this procedure, causing severe complications such as liver failure, biliary duct necrosis, perforation of the stomach, and ischemic ulcer $[52,53]$.

In order to avoid these complications, an interdisciplinary approach was introduced. Preoperative digital subtraction angiography with two catheters intubating the celiac trunk and the SMA provides important information about the status of the relevant vessels [53]. In the case of preexisting celiac trunk stenosis, spontaneous collateral flow can be seen from the SMA over pancreaticoduodenal arcades to the GDA supplying the hepatic artery. If no stenosis is present, a test occlusion of the celiac trunk with a balloon catheter can be employed to provoke collateral flow and to confirm thereby the existence of sufficient collateral arteries ( $\bullet$ Fig. 4) [53]. To enhance the collateral flow already before the operation, which follows typically one week later, embo- 


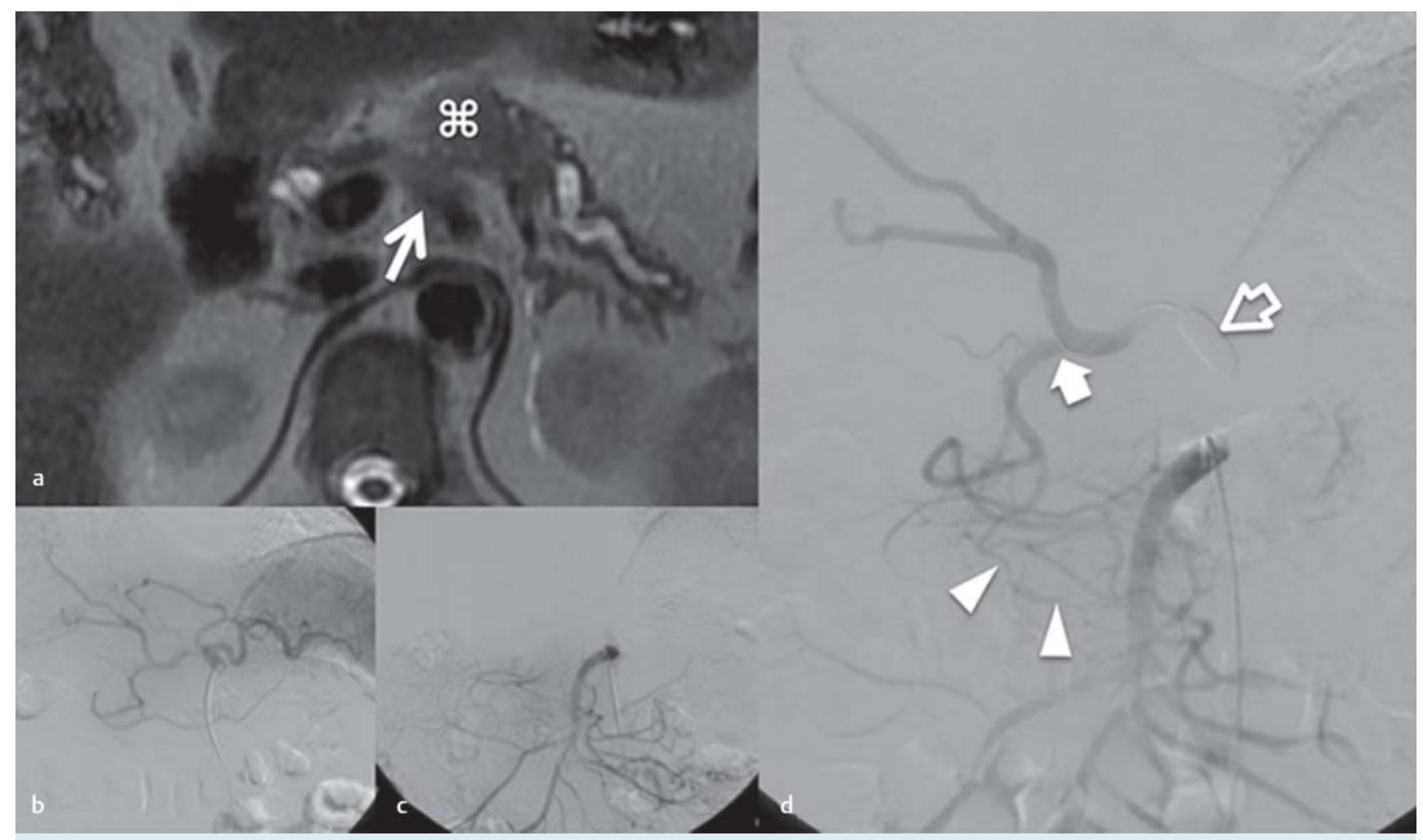

Fig. 4 T2-weighted MRI a of a carcinoma of the pancreatic corpus (asterisk) with infiltration around the celiac trunk (arrow). Selective celiaco- $\mathbf{b}$ and mesentericography c show no spontaneous collateral flow from the superior mesenteric artery to the hepatic arteries. With test occlusion of the celiac trunk $\mathbf{d}$ with a balloon (empty arrow) presence of sufficient collaterals from the superior mesenteric artery over pancreaticoduodenal arcades (arrow heads) to the gastroduodenal artery and the proper hepatic artery (block arrow) can be confirmed before definite coil embolization and subsequent en-bloc pancreatic left and celiac trunk resection.
Abb. 4 T2-gewichtete MRT a eines Pankreaskorpuskarzinoms (Stern) mit Infiltration um den Tr. coeliacus (Pfeil). Die selective Coeliaco- b und Mesentericographie c zeigt keinen spontanen Kollateralfluss von der A. mesenterica sup. zu den Leberarterien. Mit einer Testokklusion des Tr. coeliacus d mit einem Ballon (leerer Pfeil) kann die Existenz suffizienter Kollateralen von der A. mesenterica sup. über pancreatikoduodenale Arkaden (Pfeilspitzen) zur A. gastroduodenalis und A. hepatica propria vor einer definitiven Coilembolisation der zöliakalen Achse und Pankreaslinksresektion mit Trunkusresektion geprüft werden. lization of the celiac trunk is recommended in most reports on this approach as this "training" of collateralization reliably prevents ischemic complications $[53,54]$.

\section{Conclusion}

\section{$\nabla$}

Surgical exploration is the gold standard for the determination of tumor resectability of pancreatic ductal adenocarcinoma. Preoperative imaging by CT or MRI can identify clearly unresectable tumors and is essential for surgical planning in resectable and borderline resectable patients.

Radiologic resectability assessment comprises location and extent of the primary tumor including contact to adjacent vessels, vessel anatomy, presence of liver metastases, signs of peritoneal carcinomatosis, and presence of lymph node metastases.

Even with modern imaging technologies, false-positive signs of unresectability may occur. Therefore, the indication for surgical exploration should be made broadly to not preclude any patient from the chance for complete tumor resection.

\section{References}

1 Ferlay J, Shin HR, Bray F et al. Estimates of worldwide burden of cancer in 2008: GLOBOCAN 2008. Int J Cancer 2010; 127: 2893-2917

2 Bahra M, Neumann U. Surgical techniques for resectable pancreatic cancer. Recent Results Cancer Res 2008; 177: 29- 38

3 Barugola G, Partelli S, Marcucci S et al. Resectable pancreatic cancer: who really benefits from resection? Ann Surg Oncol 2009; 16: 3316-3322

4 Walter J, Nier A, Rose T et al. Palliative partial pancreaticoduodenectomy impairs quality of life compared to bypass surgery in patients with advanced adenocarcinoma of the pancreatic head. Eur J Surg Oncol 2011; 37: 798-804

5 Grenacher L, Klauss M, Dukic L et al. Hochauflösende Bildgebung beim Pankreaskarzinom: Prospektiver Vergleich von MRT und 4-ZeilenSpiral-CT. Fortschr Röntgenstr 2004; 176: 1624-1633

6 Buerke B, Heiundel W, Wessling J. Differenzialdiagnose und radiologisches Management von zystischen Tumoren des Pankreas. Fortschr Röntgenstr 2010; 182: 852-860

7 Grieser C, Heine G, Steffen IG et al. Morphological Analysis and Differentiation of Benign Cystic Neoplasms of the Pancreas Using Computed Tomography and Magnetic Resonance Imaging. Fortschr Röntgenstr 2012, [Epub ahead of print]. DOI: 10.1055/s-0032-1325551

8 Hartwig W, Hackert T, Hinz $U$ et al. Multivisceral resection for pancreatic malignancies: risk-analysis and long-term outcome. Ann Surg 2009; 250: $81-87$

9 Fletcher JG, Wiersema MJ, Farrell MA et al. Pancreatic malignancy: value of arterial, pancreatic, and hepatic phase imaging with multi-detector row CT. Radiology 2003; 229: 81 - 90

10 Koelblinger C, Ba-Ssalamah A, Goetzinger P et al. Gadobenate dimeglumine-enhanced 3.0-T MR imaging versus multiphasic 64-detector row 
CT: prospective evaluation in patients suspected of having pancreatic cancer. Radiology 2011; 259: 757-766

11 Fukukura Y, Takumi K, Kamiyama T et al. Pancreatic adenocarcinoma: a comparison of automatic bolus tracking and empirical scan delay. Abdom Imaging 2010; 35: 548-555

12 Partelli S, Crippa S, Barugola G et al. Splenic artery invasion in pancreatic adenocarcinoma of the body and tail: a novel prognostic parameter for patient selection. Ann Surg Oncol 2011; 18: 3608-3614

13 Seufferlein T, Adler G. Die S3-Leitlinie Exokrines Pankreaskarzinom. Med Klin (Munich) 2009; 104: 869-874

14 Boggi U, Del Chiaro M, Croce C et al. Prognostic implications of tumor invasion or adhesion to peripancreatic vessels in resected pancreatic cancer. Surgery 2009; 146: 869-881

15 Bilimoria $K Y$, Bentrem DJ, Ko CY et al. Validation of the 6th edition AJCC Pancreatic Cancer Staging System: report from the National Cancer Database. Cancer 2007; 110: 738 - 744

16 Yekebas EF, Bogoevski D, Cataldegirmen $G$ et al. En bloc vascular resection for locally advanced pancreatic malignancies infiltrating major blood vessels: perioperative outcome and long-term survival in 136 patients. Ann Surg 2008; 247: 300-309

17 Krumm P, Schraml C, Bretschneider C et al. Depiction of variants of the portal confluence venous system using multidetector row CT: analysis of 916 cases. Fortschr Röntgenstr 2011; 183: 1123-1129

18 Loyer EM, David CL, Dubrow RA et al. Vascular involvement in pancreatic adenocarcinoma: reassessment by thin-section CT. Abdom Imaging 1996; 21: $202-206$

19 Nakao A, Kanzaki A, Fujii T et al. Correlation between radiographic classification and pathological grade of portal vein wall invasion in pancreatic head cancer. Ann Surg 2012; 255: 103 - 108

20 Grieser C, Steffen IG, Grajewski L et al. Preoperative multidetector row computed tomography for evaluation and assessment of resection criteria in patients with pancreatic masses. Acta Radiol 2010; 51: 1067-1077

21 Mollberg N, Rahbari NN, Koch $M$ et al. Arterial resection during pancreatectomy for pancreatic cancer: a systematic review and meta-analysis. Ann Surg 2011; 254: 882 - 893

22 Lopez Hänninen E, Amthauer H, Hosten $N$ et al. Prospective evaluation of pancreatic tumors: accuracy of MR imaging with MR cholangiopancreatography and MR angiography. Radiology 2002; 224: 34-41

23 Soriano A, Castells A, Ayuso C et al. Preoperative staging and tumor resectability assessment of pancreatic cancer: prospective study comparing endoscopic ultrasonography, helical computed tomography, magnetic resonance imaging, and angiography. Am J Gastroenterol 2004; 99: $492-501$

24 Lu DS, Reber HA, Krasny RM et al. Local staging of pancreatic cancer: criteria for unresectability of major vessels as revealed by pancreaticphase, thin-section helical CT. Am J Roentgenol Am J Roentgenol 1997; 168: $1439-1443$

25 Grieser C, Denecke T, Steffen IG et al. Multidetector computed tomography for preoperative assessment of hepatic vasculature and prediction of splenic artery steal syndrome in patients with liver cirrhosis before transplantation. Eur Radiol 2010; 20: 108-117

26 Kaneko OF, Lee DM, Wong J et al. Performance of multidetector computed tomographic angiography in determining surgical resectability of pancreatic head adenocarcinoma. J Comput Assist Tomogr 2010; 34: $732-738$

27 Mayo SC, Austin DF, Sheppard BC et al. Evolving preoperative evaluation of patients with pancreatic cancer: does laparoscopy have a role in the current era? J Am Coll Surg 2009; 208: 87-95

28 Balachandran A, Darden DL, Tamm EP et al. Arterial variants in pancreatic adenocarcinoma. Abdom Imaging 2008; 33: 214-221

29 Pfannenberg C, Schwenzer NF, Bruecher BL. State-of-the-Art-Bildgebung bei Peritonealkarzinose. Fortschr Röntgenstr 2012; 184: 205-213

30 Glant JA, Waters JA, House MG et al. Does the interval from imaging to operation affect the rate of unanticipated metastasis encountered during operation for pancreatic adenocarcinoma? Surgery 2011; 150: 607-616

31 Strobel K, Heinrich S, Bhure U et al. Contrast-enhanced 18F-FDG PET/ CT: 1-stop-shop imaging for assessing the resectability of pancreatic cancer. J Nucl Med 2008; 49: 1408-1413

32 Appel BL, Tolat P, Evans DB et al. Current staging systems for pancreatic cancer. Cancer J 2012; 18: 539-549

33 Niekel MC, Bipat S, Stoker J. Diagnostic imaging of colorectal liver metastases with CT, MR imaging, FDG PET, and/or FDG PET/CT: a meta-analysis of prospective studies including patients who have not previously undergone treatment. Radiology 2010; 257: 674-684
34 Löwenthal D, Zeile M, Lim WY et al. Detection and characterisation of focal liver lesions in colorectal carcinoma patients: comparison of diffusion-weighted and Gd-EOB-DTPA enhanced MR imaging. Eur Radiol 2011; $21: 832-840$

35 Coenegrachts K, De Geeter F, ter Beek L et al. Comparison of MRI (including SS SE-EPI and SPIO-enhanced MRI) and FDG-PET/CT for the detection of colorectal liver metastases. Eur Radiol 2009; 19: 370-379

36 Izuishi K, Yamamoto Y, Sano T et al. Impact of 18-fluorodeoxyglucose positron emission tomography on the management of pancreatic cancer. J Gastrointest Surg 2010; 14: 1151-1158

37 Kamphues C, Bova R, Schricke D et al. Postoperative complications deteriorate long-term outcome in pancreatic cancer patients. Ann Surg Oncol 2012; 19: 856-856

38 Pai RK, Beck AH, Mitchem J et al. Pattern of lymph node involvement and prognosis in pancreatic adenocarcinoma: direct lymph node invasion has similar survival to node-negative disease. Am J Surg Pathol 2011; 35: $228-234$

39 Slidell MB, Chang DC, Cameron JL et al. Impact of total lymph node count and lymph node ratio on staging and survival after pancreatectomy for pancreatic adenocarcinoma: a large, population-based analysis. Ann Surg Oncol 2008; 15: 165 - 174

40 Imai $H$, Doi R, Kanazawa $H$ et al. Preoperative assessment of para-aortic lymph node metastasis in patients with pancreatic cancer. Int J Clin Oncol 2010; 15: 294-300

41 Yamada S, Fujii T, Sugimoto $H$ et al. Pancreatic cancer with distant metastases: a contraindication for radical surgery? Hepatogastroenterology 2009; 56: $881-5$

42 Hosein PJ, Macintyre J, Kawamura C et al. A retrospective study of neoadjuvant FOLFIRINOX in unresectable or borderline-resectable locally advanced pancreatic adenocarcinoma. BMC Cancer 2012; 12: 199

43 Denecke T, Rau B, Hoffmann KT et al. Comparison of CT, MRI and FDGPET in response prediction of patients with locally advanced rectal cancer after multimodal preoperative therapy: is there a benefit in using functional imaging? Eur Radiol 2005; 15: 1658 - 1666

44 Denecke T, Hundsdörfer P, Misch D et al. Assessment of histological response of paediatric bone sarcomas using FDG PET in comparison to morphological volume measurement and standardized MRI parameters. Eur J Nucl Med Mol Imaging 2010; 37: 1842-1853

45 Tateishi $U$, Miyake M, Nagaoka $T$ et al. Neoadjuvant chemotherapy in breast cancer: prediction of pathologic response with PET/CT and dynamic contrast-enhanced MR imaging-prospective assessment. Radiology 2012; 263: 53-63

46 Tamm EP, Loyer EM, Faria $S$ et al. Staging of pancreatic cancer with multidetector $\mathrm{CT}$ in the setting of preoperative chemoradiation therapy. Abdom Imaging 2006; 31: $568-574$

$47 \mathrm{Katz} \mathrm{MH}$, Fleming JB, Bhosale P et al. Response of borderline resectable pancreatic cancer to neoadjuvant therapy is not reflected by radiographic indicators. Cancer 2012, [Epub ahead of print]. DOI: 10.1002/ cncr.27636

48 Donahue TR, Isacoff WH, Hines OJ et al. Downstaging chemotherapy and alteration in the classic computed tomography/magnetic resonance imaging signs of vascular involvement in patients with pancreaticobiliary malignant tumors: influence on patient selection for surgery. Arch Surg 2011; 146: 836-843

49 Kim YE, Park MS, Hong HS et al. Effects of neoadjuvant combined chemotherapy and radiation therapy on the CT evaluation of resectability and staging in patients with pancreatic head cancer. Radiology 2009; 250: $758-765$

50 Sperti C, Berselli M, Pedrazzoli S. Distal pancreatectomy for body-tail pancreatic cancer: is there a role for celiac axis resection? Pancreatology 2010; 10 : $491-498$

51 Kondo S, Katoh $H$, Hirano $S$ et al. Ischemic gastropathy after distal pancreatectomy with celiac axis resection. Surg Today 2004; 34: 337-340

52 Andreou A, Glanemann M, Guckelberger $O$ et al. Pankreaslinksresektion mit Splenektomie und Resektion des Truncus coeliacus bei einem Pankreaskorpuskarzinom mit Infiltration des Truncus coeliacus. Med Klin (Munich) 2010; 105: 227-231

53 Denecke T, Andreou A, Podrabsky P et al. Distal pancreatectomy with en bloc resection of the celiac trunk for extended pancreatic tumor disease: an interdisciplinary approach. Cardiovasc Intervent Radiol 2011; 34: $1058-1064$

54 Kondo S, Katoh H, Shimizu $T$ et al. Preoperative embolization of the common hepatic artery in preparation for radical pancreatectomy for pancreas body cancer. Hepatogastroenterology 2000; 47: 1447-1449 